\title{
Potential toxicity and safety evaluation of nanomaterials for the respiratory system and lung cancer
}

This article was published in the following Dove Press journal:

Lung Cancer:Targets and Therapy

28 November 2013

Number of times this article has been viewed

\author{
Thomais Vlachogianni' \\ Konstantinos Fiotakis' \\ Spyridon Loridas' \\ Stamatis Perdicaris ${ }^{2}$ \\ Athanasios Valavanidis' \\ 'Department of Chemistry, Free \\ Radicals Research Group, ${ }^{2}$ Faculty \\ of Pharmacy, Department of \\ Pharmacognosy and Natural Product \\ Chemistry, University of Athens, \\ Athens, Greece
}

\begin{abstract}
Engineered nanomaterials (ENMs) are a diverse group of materials finding increasing use in manufacturing, computing, food, pharmaceuticals, and biomedicine due to their very small size and exceptional properties. Health and safety concerns for ENMs have forced regulatory agencies to consider preventive measures and regulations for workers' health and safety protection. Respiratory system toxicity from inhalable ENMs is the most important concern to health specialists. In this review, we focus on similarities and differences between conventional microparticles (diameters in $\mathrm{mm}$ and $\mu \mathrm{m}$ ), which have been previously studied, and nanoparticles (sizes between 1 and $100 \mathrm{~nm}$ ) in terms of size, composition, and mechanisms of action in biological systems. In past decades, respirable particulate matter (PM), asbestos fibers, crystalline silicate, and various amorphous dusts have been studied, and epidemiological evidence has shown how dangerous they are to human health, especially from exposure in working environments. Scientific evidence has shown that there is a close connection between respirable PM and pulmonary oxidative stress through the generation of reactive oxygen species (ROS) and reactive nitrogen species (RNS). There is a close connection between oxidative stress in the cell and the elicitation of an inflammatory response via pro-inflammatory gene transcription. Inflammatory processes increase the risk for lung cancer. Studies in vitro and in vivo in the last decade have shown that engineered nanoparticles (ENPs) at various doses can cause ROS generation, oxidative stress, and pro-inflammatory gene expression in the cell. It is assumed that ENPs have the potential to cause acute respiratory diseases and probably lung cancer in humans. The situation regarding chronic exposure at low doses is more complicated. The long-term accumulation of ENPs in the respiratory system cannot be excluded. However, at present, exposure data for the general public regarding ENPs are not available.
\end{abstract}

Keywords: engineered nanomaterials, nanoparticles, oxidative stress, inflammation, safety evaluation, respiratory diseases

\section{Introduction}

In the beginning of the 21st century, engineered nanomaterials (ENMs) and their applications in a great range of biomedical, pharmaceutical, and consumer products caused great excitement among the scientific and engineering communities. Total worldwide sales revenues for nanotechnology were US\$11.6 billion in 2009, and are expected to increase to more than US\$26 billion (11\% increase) in $2015 .{ }^{1}$ The workforce in nanotechnology products is expected to reach 6 million by 2020, and annual investment in global nanotechnology research and development (R\&D) will increase substantially from US\$17.8 billion (2010). ${ }^{2}$

Much has been written in the scientific literature about ENMs and the possible dangers to human health and the environment. ${ }^{3,4}$ ENMs are a diverse group of
Correspondence: Athanasios Valavanidis Department of Chemistry, University of Athens, University Campus Zografou, 15784 Athens, Greece

Tel +302107274763

Fax +30210727 4761

Email valavanidis@chem.uoa.gr 
materials finding increasing use in manufacturing, energy, motorcars, textiles, computing, food, pharmaceuticals, and biomedicinal products due to their very small size and exceptional engineered properties. The percentage distribution of ENM applications in 2007 was as follows: chemicals $53 \%$; semiconductors 34\%; electronics 7\%; aerospace and defence $3 \%$; pharmaceuticals and healthcare $2 \%$; and automotive $1 \% .^{5-8}$

From the beginning, the applications of nanotechnology products raised concerns among toxicologists and occupational health and safety (H\&S) specialists over risks to human health and the environment. Adverse health effects from ENMs are expected to be observed in workers who are exposed during the manufacturing process, preparation, and formulation of ENMs in various stages of product formulation. Consumers are the second line of concern regarding ENM exposure during their use, especially with inhalation or skin penetration. Another group of ENM users are patients receiving nano-biomedical applications and delivered pharmaceuticals with the help of nanoparticle technologies. Exposure may therefore occur in a variety of occupational settings where ENMs are used, handled, or processed and consequently become airborne and can be inhaled, or come into contact with the skin; for example, in contexts from healthcare or laboratory work, to maintenance or construction work. ${ }^{9-12}$

The most important route of exposure to various particles (environmental or occupational) remains inhalation and subsequent risks to the respiratory system because of their minute size and penetration into the lung's alveoli. Coarse particles range in size between $10,000 \mathrm{~nm}$ and $2,500 \mathrm{~nm}\left(1 \mathrm{~nm}=10^{-9} \mathrm{~m}\right)$; fine particles between 2,500 nm and $100 \mathrm{~nm}$; and ultrafine particles (UFPs) between 100 $\mathrm{nm}$ and $1 \mathrm{~nm}$.

Studies in recent decades have indicated that fine particles of toxic and carcinogenic chemicals with high persistency can influence toxicological mechanisms. These particles have the potential to generate reactive oxygen species (ROS), oxidative stress, inflammation, and carcinogenic mechanisms in the respiratory system. ${ }^{13-16}$ Additionally, tobacco smoke and environmental airborne respirable particulate matter (PM) can act synergistically to increase inflammatory reactions and risk for lung carcinogenesis. ${ }^{17,18}$

$\mathrm{H} \& \mathrm{~S}$ concerns for ENMs have forced regulatory agencies to consider preventive measures and regulations. The European Union (EU) legislation on worker protection applies to nanomaterials, although it does not refer explicitly to them. Of particular relevance are the Framework Directive 1989/391/EEC (H\&S of workers at work), the Chemical Agent Directive 1998/24/EC (H\&S of workers from the risks related to chemical agents at work), and the Carcinogen and Mutagen Directive 2004/37/EC (protection of workers from the risks related to exposure to carcinogens or mutagens). ENMs are also covered by the legislation on chemicals (EC 1907/2006, Registration, Evaluation, Authorisation and Restriction of Chemicals; REACH), and the CLP Regulation (Classification, Labelling and Packaging, EC No 1272/2008) that ensures that the hazards presented by chemicals are clearly communicated to workers and consumers in the EU.

The Environmental Protection Agency (EPA) and other regulatory $\mathrm{H} \& \mathrm{~S}$ bodies in the USA are using a comprehensive environmental assessment approach to identify and prioritize research to support future assessments and risk management decisions for ENMs. The EPA is using scientific methods to research what ENMs are, and how they act, travel, and change over time. The EPA's Chemical Safety and Pollution Prevention Office and other regulatory bodies in the last decade have made chemical and regulatory decisions to better protect human health and the environment from ENMs. ${ }^{19}$

The US Food and Drug Administration (FDA) regulates a wide range of products (foods, cosmetics, drugs, devices, veterinary products) that may utilize nanotechnology or contain nanomaterials. In April 2012, the US FDA issued two product-specific draft guidance documents to address the use of nanotechnology by the food and cosmetics industries as part of the US FDA's ongoing implementation of recommendations from the US FDA's 2007 Nanotechnology Task Force Report. $^{20}$

Similar H\&S laws and regulations have been initiated in other developed industrialized countries. The Organization for Economic Co-operation and Development (OECD) has introduced a database, Research into the Safety of Manufactured Nanomaterials, which helps to identify research gaps and assist researchers in future collaborative efforts. The database also assists the projects of the OECD's Working Party on Manufactured Nanomaterials (WPMN) as a resource of research information. . $^{21,22}$

$\mathrm{H} \& \mathrm{~S}$ regulations mean that employers are required to assess and manage the risks of ENMs at work. If the use and generation of ENMs cannot be eliminated or substituted with less hazardous materials and processes, worker exposure must be minimized through prevention measures, technical control measures at source, organizational safety 
measures, and, as a last resort, use of personal protection equipment.

\section{Similarities of conventional coarse, microparticles, and fine particles with engineered nanoparticles (ENPs)}

In the present paper, we use the terms "coarse", "microparticles", and "fine particles" for a range of respirable PM and mineral fibers that have been the subject of research efforts in the working environment in recent decades; whereas the size of superfine particles from combustion sources is very close to that of nanoparticles.

For comparison reasons, it is important to address similarities and differences between coarse particles, microparticles, and fine and superfine particles versus nanoparticles in terms of size, composition, and mechanisms of action in biological systems. Respirable PM, mineral fibers (eg, asbestos), crystalline silicate, amorphous dusts, and aerosols occur naturally, but most of the dangerous inhalable $\mathrm{PM}$ is anthropogenic in origin. PM from combustion is a complex, heterogeneous mixture that encompasses many different chemical components and physical characteristics, many of which have been cited as potential contributors to toxicity. Airborne combustion particles from fossil fuels are considered to be the main atmospheric particulate pollutants that can lodge in the lungs and cause oxidative stress, initiate inflammatory responses, and promote carcinogenic mechanisms to lung tissues..$^{23,24}$

Over the last few decades, many studies have been carried out with various dusts, inorganic and organic particle mineral fibers, cement dust, crystalline silica, and fly ash in the size range of $10-100 \mu \mathrm{m}$ : inhalable suspended particles with diameters of $10 \mu \mathrm{m}\left(\mathrm{PM}_{10} ; 1 \mu \mathrm{m}=10-6 \mathrm{~m}\right)$, or smaller and airborne fine particles (dynamic diameter of $\left.2.5 \mu \mathrm{m} ; \mathrm{PM}_{2.5}\right)$. UFPs have a diameter less than $100 \mathrm{~nm}$, and automobile exhaust soot is in the range of $0.01-1 \mu \mathrm{m}$ $\left(\mathrm{PM}_{0.1}\right)$. UFPs are deposited in the lungs, where they have the ability to penetrate tissue and undergo interstitialization, or to be absorbed directly into the bloodstream. Size and surface properties are very important. Exposure to UFPs, even if components are not very toxic, may cause oxidative stress and inflammatory damage and could induce lung diseases. ${ }^{25-27}$

Coarse particles and microparticles have, for decades, been the subject of numerous toxicological studies, and their relationship to respiratory adverse health effects has been observed in various occupational environments. Also, airborne $\mathrm{PM}\left(\mathrm{PM}_{10}, \mathrm{PM}_{2.5}\right.$, and $\left.\mathrm{PM}_{0.1}\right)$ in urban areas has been connected to respiratory morbidity and premature mortality by numerous epidemiologic studies. ${ }^{28-30}$

ENMs constitute an emerging man-made pollution source that is, so far, literally buried beneath much larger natural sources and ultrafine (with nanosize particles) pollution from automobile exhaust soot in urban areas. Irrespective of size,

Table I Particles with proven lung carcinogenic effects in animals and/or humans (most of the classifications are also classified by the International Agency for Research on Cancer, IARC)

\begin{tabular}{lll}
\hline $\begin{array}{l}\text { Metal oxides, mineral fibers, particles, } \\
\text { and fine and superfine particles }\end{array}$ & Source & Exposure, rat and human (IARC) \\
\hline Particulate matter PM $\left._{0.1}, \mathrm{PM}_{2.5}, \mathrm{PM}_{10}\right)$ & Ambient, inhalable air pollutants & $\begin{array}{l}\text { Possibly carcinogenic? } \\
\text { (unknown fraction) }\end{array}$ \\
$\mathrm{NiO}$ & Exhaust & + (positive, carcinogenic) \\
Quartz (crystalline silica) & Constructions & + (positive, carcinogenic) \\
Asbestos insulation & Mining & + (positive, carcinogenic) \\
Carbon black & Pigments, toner, tires & + (possibly carcinogenic) \\
Refractory ceramic fibers & Insulation & (possibly carcinogenic) \\
Wood dust & Furniture, making, saw mills & \pm carcinogenic (some types) \\
TiO ${ }_{2}$ & Pigments, sunscreens & + (positive, animals) \\
Diesel exhaust & Vehicular engines, cars & + (positive, carcinogenic) \\
Talc & Cosmetics, mining & + (positive, only animals) \\
Volcanic fly ash & Ambient & + (positive, only animals) \\
Coal mine dust, graphite, cement & Mining, occupational, paints, construction & Not classifiable \\
Iron oxides & Pigments, paramagnetic, diagnostics & \pm (mixed results) \\
\hline
\end{tabular}

Abbreviations: $\mathrm{NiO}$, nickel oxide; $\mathrm{TiO}_{2}$, titanium dioxide.

Notes: Particulate matter size is given in $\mathrm{nm}(0.1,2.5$, and $10 \mathrm{~nm})$ Data from Knaapen et al. ${ }^{31}$ Adapted with permission from Borm PJ, Schins RP, Albrecht C. Inhaled particles and lung cancer, part B: paradigms and risk assessment. Int J Cancer. 2004;1 I0(I):3-14. ${ }^{32}$ 
some particles, such as metal dusts, welding fumes, and quartz dust, are inherently toxic, while others have a much lower toxicity, but can cause inflammatory toxic effects in the lungs. This is especially true for biodurable particles without known specific toxicity, including mineral dusts, carbon black, coal-mine dust, titanium dioxide $\left(\mathrm{TiO}_{2}\right)$, and others as listed in Table 1.

Scientific studies have identified a variety of mechanisms that play key roles in particle-induced chronic and acute respiratory diseases. In high concentrations and with prolonged exposure in occupational environments, PM can advance lung carcinogenesis. The most important mechanisms are 1) generation and oxidative action by ROS and reactive nitrogen species (RNS), causing extensive lipid peroxidation (cellular membranes), enzyme, and DNA damage; 2) oxidative stress; 3) ROS-stimulated signaling moieties involved in many carcinogenic pathways (induction of cell and tissue proliferation, angiogenesis, etc); and 4) inflammation-driven processes with high significance for lung mutagenesis and carcinogenesis. ${ }^{33-35}$

In vitro observations demonstrate inflammation-independent particle effects related to the physicochemical properties of particles (eg, surface activity, polycyclic aromatic hydrocarbons [PAHs], nitro-PAHs, metals with redox potential, etc); however, the outcomes of in vitro and in vivo studies should be interpreted with caution for risk-assessment purposes, as they are mainly the result of high-dose exposures for long periods of time that are unlikely to be relevant for the human situation, ie, exposure in urban environments. ${ }^{36}$

Additionally, many epidemiologic studies have provided experimental support for associations between various microscale PM exposure and adverse pulmonary effects in occupational environments. Upon deposition, PMs can trigger ROS/RNS production, inflammatory processes that potential lead to airway obstruction, compromised gas exchange, and the exacerbation of pre-existing conditions. Occupational and urban exposure to PM is associated with lung pathology, including chronic obstructive pulmonary disease (COPD), bronchitis, asthma, and lung cancer. ${ }^{37-39}$

\section{Differences between ENPs and inhalable mineral fibers, coarse, micro-size, and fine particles}

Experimental results with ENPs indicate that various physicochemical characteristics and factors cause nanoparticles to behave significantly differently than conventional mineral fibers, and coarse or micro-size particles (see Table 2). ${ }^{40,41}$

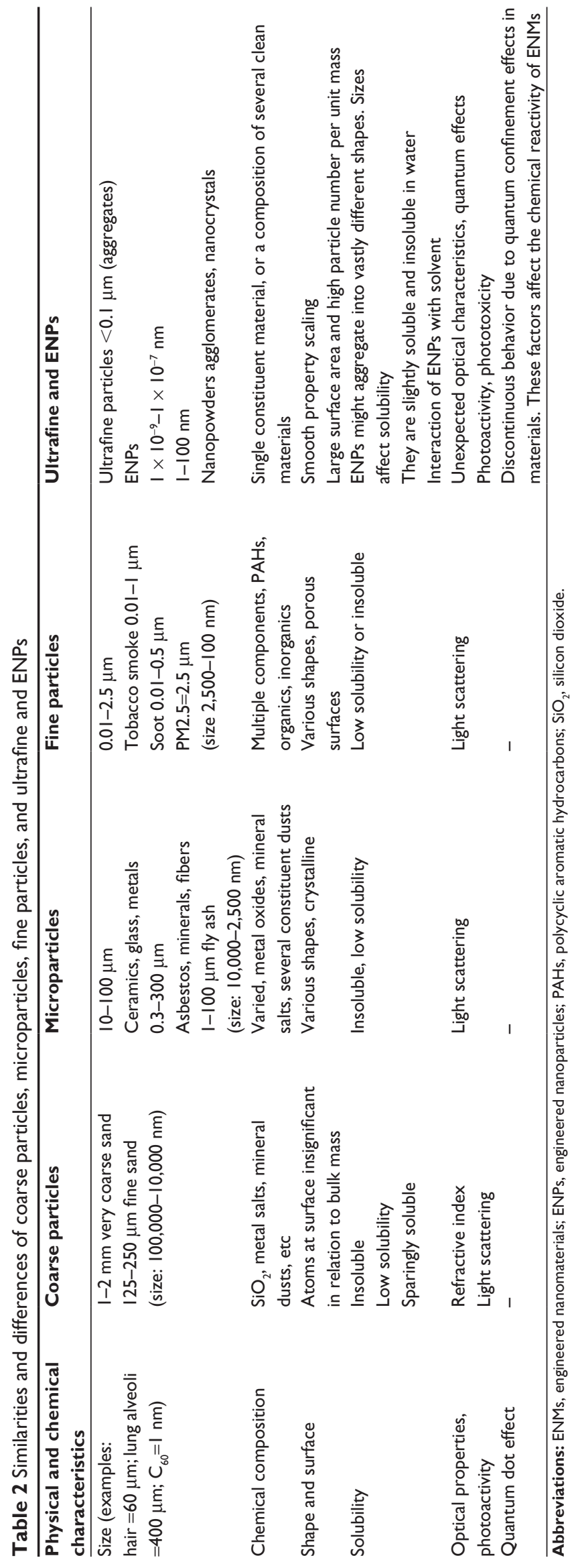




\section{Shape and surface}

In ENPs, the arrangement of molecules on the surface causes smooth property scaling due to the fraction of atoms at the surface. In bulk materials larger than $1 \mu \mathrm{m}$, the percentage of atoms at the surface is insignificant in relation to the number of atoms in the bulk mass of the material. The unusual properties of ENPs are therefore largely due to the large surface area and high particle numbers per unit mass, which greatly influence their cellular uptake. Probing these various interfaces allows the development of predictive relationships between structure and activity that are determined by nanomaterial properties such as size, shape, surface chemistry, roughness, and surface coatings. All these physicochemical aspects have proved very important with regards to the safe use of nanomaterials. ${ }^{42,43}$

Examining the influence of shape and size of nanoparticles on cell interactions has proved crucial in toxicity. Another very important factor is that, even though nanoparticles display a certain size after synthesis, during in vitro and in vivo studies they might aggregate into vastly different shapes and sizes. ${ }^{44}$ Nanoparticle behavior, ie, dispersion or aggregation, plays an important role in toxicity (including photo-oxidation products). Carbon nanotubes (CNTs) apparently have greater pulmonary toxicity (inflammation, granuloma) in mice than does fine-scale carbon graphite, and their metal content may affect toxicity. ${ }^{45}$

\section{Solubility}

Toxic effects of ENPs may be attributed to two different actions: chemical toxicity based on the chemical composition (eg, release of toxic ions), and particle surface catalyzed reactions that generate damaging ROS. Differentiating between these two types of cytotoxicity is not straightforward, especially when particles are partially dissolved during culture treatment. In order to test this proposal, seven different industrially relevant oxide nanoparticles were tested with two well established cell lines (one human, one rodent). The results confirmed that solubility greatly affected the cell culture response to the nanoparticles. Therefore, it appears reasonable to group the different nanoparticles into slightly soluble and insoluble nanomaterials. ${ }^{46}$

Another physical phenomenon that drew the attention of scientists researching ENPs was dissolution (the dynamic process by which a particle goes into the solution phase to form a homogeneous mixture). Translocation and disposition have been shown to play a key role in the fate and biological effects of inhaled particles and fibers. Concepts that have been applied in the micron size range can be usefully applied to the nanoscale range. Solute concentration, surface area, surface morphology, surface energy, dissolution layer properties, adsorbing species, and aggregation are relevant parameters in considering dissolution at the nanoscale. Dissolution is a critical step for some ENPs in determining biological fate in the environment and within the human body. ${ }^{47,48}$

\section{Optical properties, photoactivity, redox potential}

ENPs often possess unexpected optical characteristics as they are small enough to confine their electrons and produce quantum effects. Changes in optical properties at the nanoscale level are the result of electrons not being as free to move as they are in bulk materials. The very large surface-to-volume (S/V) ratio has a major influence on their optical and surface properties. As a result, semiconductor nanomaterials have attracted significant attention in research and applications in energy conversion, photonics, and biomedicine. ENPs have played a critical role in many important chemical reactions as reactants or photocatalysts and their reactivities are often altered or enhanced due to size-dependent changes in their redox potentials and high density of active surface states. Although the potential for the generation of ROS by ENPs is useful in various applications (degradation of pollutants), it can be dangerous in the respiratory system or to aquatic organisms (from nanomaterial waste in the aquatic environment). ${ }^{49,50}$

A typical example is $\mathrm{TiO}_{2}$ nanoparticles, which are highly photoactive; their photocatalyst functions drive much of the application demand for $\mathrm{TiO}_{2}$. $\mathrm{TiO}_{2}$ has been used in various ENMs, especially in antibacterial coatings and wastewater disinfection. However, at the same time, $\mathrm{TiO}_{2}$ has the potential for cytotoxicity. In vivo tests of $\mathrm{TiO}_{2}$ toxicity with aquatic organisms have typically shown low toxicity, and results across studies have been variable. Overall, oxidative stress in seawater contaminated by $\mathrm{TiO}_{2}$ can decrease the resiliency of marine ecosystems. Phototoxicity must be considered when evaluating the environmental impacts of various ENMs. ${ }^{51}$

\section{Quantum dot (QD) effects}

ENPs show discontinuous behavior due to quantum confinement effects in materials with delocalized electrons. QD factors affect the chemical reactivity of ENMs, 
as well as their mechanical, optical, electric, and magnetic properties (superparamagnetism). These properties make ENMs superior to various applications (site-specific medical imaging, drug delivery, etc) but also increase the cytotoxicity of ENMs. QDs are an additional characteristic affecting a rational risk assessment of ENMs. There are mechanisms by which QDs can damage cells, including oxidative stress elicited by ROS. ${ }^{52}$

\section{Suspensions}

Suspensions of ENPs are possible, since the interaction of the particle surface with the solvent is strong enough to overcome density differences, which otherwise usually results in a material either sinking or floating in a liquid. Suspensions of ENPs in aquatic environments are potentially dangerous to aquatic organisms. Experiments regarding the potential ecotoxicity of nanosized $\mathrm{TiO}_{2}$, silicon dioxide $\left(\mathrm{SiO}_{2}\right)$, and zinc oxide $(\mathrm{ZnO})$ in water suspensions were conducted in test organisms. These photosensitive nanomaterials were observed to be harmful. ${ }^{53}$ Similarly, the potential for ecotoxicity from various metal oxide nanoparticle suspensions released to aquatic environments were tested with zebrafish 96 hour embryo-larval bioassay. Results demonstrated that ENPs of $\mathrm{ZnO}$ were very toxic to zebrafish embryos and larvae. ${ }^{54}$

\section{Chemical composition}

ENMs are considered chemically uniform by one or more chemical pure constituents. Coarse minerals are salts with impurities, microparticles can have two or more components, combustion products are highly toxic pollutants with mixed compositions of oxidative, toxic, and carcinogenic substances (heavy metals, PAHs, dioxins, etc). Nanoparticles can be composed of a single pure constituent material or be a composite of two to three chemical materials.

Toxicological results indicate that most ENPs have produced an array of different toxic effects in many different types of in vivo and in vitro studies. The types of effects that ENPs have produced are those on the pulmonary, cardiac, reproductive, renal, and cutaneous systems, as well as on various cell lines. After inhalation exposure, significant accumulations of ENPs have been found in the lungs, brain, liver, spleen, and bones of test species. Toxicity of ENPs has been linked to their surface properties. Soluble ENPs are rendered toxic because of their constituents; however, the situation is entirely different for insoluble ENPs. Stable metal oxides do not show any toxicity, whereas metallic ENPs that have redox potential may be cytotoxic and genotoxic..$^{55}$

To illustrate size differences between a conventional size strand of hair, microparticles, and nanoparticles, Figure 1 presents one carbon microparticle with a diameter of $60 \mu \mathrm{m}$, which has a mass of $0.3 \mu \mathrm{g}$ and a surface area of $0.01 \mathrm{~mm}^{2}$. Nanoparticles with a diameter of $600 \mathrm{~nm}$ can have 1 million particles, whereas nanoparticles with a diameter of $60 \mathrm{~nm}$ have a surface area of $11.3 \mathrm{~mm}^{2}$ and consist of 1 billion nanoparticles (Figure 1). The $\mathrm{S} / \mathrm{V}$ ratio (or mass) for a particle with a diameter of $60 \mathrm{~nm}$ is 1,000 times larger than a particle with a diameter of $60 \mu \mathrm{m}$. As a result, chemical reactivity is substantially enhanced. The

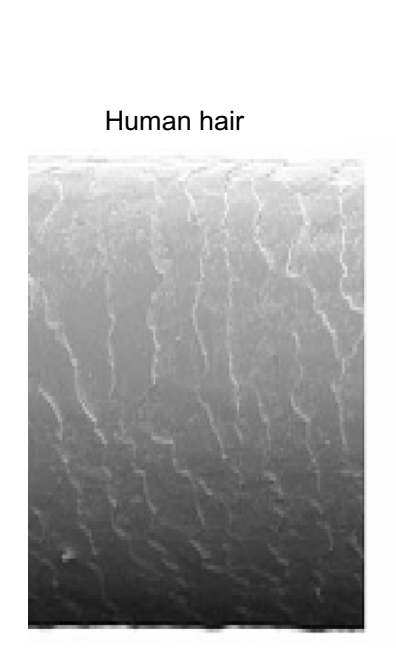

1 microparticle $60 \mu \mathrm{m}$ diameter (size of human hair)

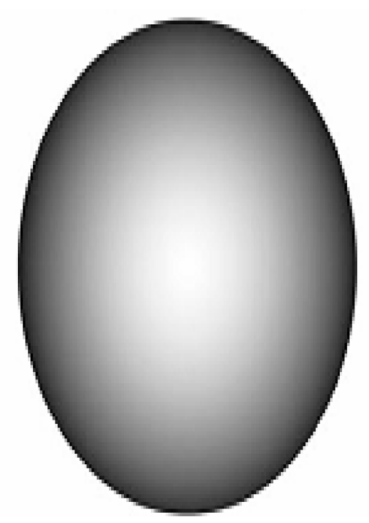

1 million particles $600 \mathrm{~nm}$ diameter

1 billion nanoparticles

$60 \mathrm{~nm}$ diameter
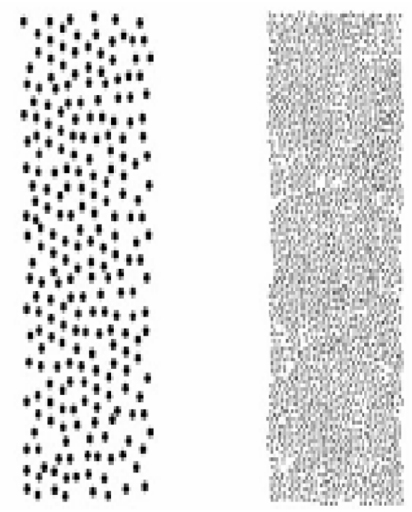

Figure I Comparative sizes for (from left to right) human hair (60 $\mu \mathrm{m}$ diameter), spherical microparticle of the same diameter, I million particles $600 \mathrm{~nm}$ diameter, and I billion nanoparticles of $60 \mathrm{~nm}$ diameter.

Note: Reproduced from Buzea C, Pacheco II, Robbie K. Nanomaterials and nanoparticles: sources and toxicity. Biointerphases. 2007;2(4):MR I7-MR7I.42

The article/figure is published under Creative Commons License 2.0 CC-BY.38. 
atoms situated at the surface have fewer neighbors than bulk atoms, resulting in lower binding energy per atom. Reduced binding energy per atom can cause a decrease in melting point. ${ }^{42}$

\section{Potential respiratory toxicity and carcinogenesis of inhaled ENPs}

Based on past toxicological studies of the relationship between inhalation of PM (so-called conventional particles, coarse, fine, and superfine) and respiratory diseases, scientists directed their attention to similar effects relating to ENPs. The potential of ENPs inhaled under various exposure conditions to cause oxidative stress in the respiratory system and, subsequently, inflammation and initiation of lung carcinogenesis has been under investigation in the last decade. ${ }^{56-58}$

Experimental data have shown limited evidence that ENPs cause acute respiratory diseases and lung cancer in humans. Until now, manufactured microparticles and UFPs (nanosize), such as $\mathrm{TiO}_{2}$, carbon black, crystalline silica, aluminum dust, etc, have been produced for many decades, but epidemiologic evidence of an increased cancer risk from exposure to these particles in humans is very limited. ${ }^{59,60}$ However, in the case of long-term exposure to asbestos fibers, especially blue asbestos (crocidolite) in occupational environments, there is positive evidence of increased risk for lung carcinogenesis, multiplying substantially in combination with tobacco smoking because of synergistic effects. ${ }^{61-63}$

Nanosized durable fibrous materials such as CNTs have raised safety concerns similar to those raised about asbestos fibers. However, the mechanism by which particulates with ultrafine structure cause inflammation and ultimately cancer (eg, malignant mesothelioma and lung cancer) is largely unknown. This is partially because the particulates are not uniform and they vary in a plethora of factors (length, diameter, surface area, density, shape, contaminant metals, and crystallinity). These factors play an important role in particulate toxicity both in vitro and in vivo. Thus, the elicited biological responses from fibrous nanomaterials are very complicated. ${ }^{64}$

Toxicologists in the last decade have investigated many mechanistic pathways to test the potential for ENPs to initiate inflammation and subsequently to cause cancer, based on data from toxicology of conventional particles and on data accumulated so far. The evidence thus far does suggest that harmful nanoparticles have, in general, the same types of effects at the cellular level as coarse and bulkier particles. Scientists have to make the distinction that ENPs are heterogeneous, like larger particles, in the type of damage they can cause to the respiratory system. Results showed that ENPs have the ability to increase the formation of ROS/RNS and other oxidants, to cause oxidative stress, inflammation and initiation (and promotion) of carcinogenic mechanisms or/and genotoxicity. ${ }^{65-67}$

\section{Are ENPs capable of initiating biological mechanisms of carcinogenesis?}

Currently, there is little evidence as to the carcinogenic effects of ENPs in humans. In addition, there are few recent in vivo studies addressing a cancer endpoint for ENPs. We can examine the stages of mechanisms leading to initiation of carcinogenic processes.

\section{Generation of ROS/RNS by ENPs in the biological cell environment}

The first indication of biological damaging effects is the ability of the nanoparticle to generate ROS or RNS in the vicinity of or inside the cell. This is normally the response of airway epithelium to particles entering the lungs through inhalation. The most important oxidative ROS and RNS are the hydroxyl radical $\left(\mathrm{HO}^{*}\right)$, the superoxide anion $\left(\mathrm{O}_{2}{ }^{--}\right)$, alkoxyl radical $\left(\mathrm{RO}^{\circ}\right)$, hydrogen peroxide $\left(\mathrm{H}_{2} \mathrm{O}_{2}\right)$, and the peroxynitrite $\mathrm{O}=\mathrm{ONO}^{-}$. They can cause oxidative damage to lipid membranes, protein-enzymes, and cellular or mitochondrial DNA (cDNA, mtDNA). ${ }^{68,69}$

Past studies show that respiratory exposure to conventional PM is thought to impact on genotoxicity as well as on cell proliferation via the PM's ability to generate ROS and RNS. Although evidence suggests that ROS/RNS mediate particle-induced genotoxicity and mutagenesis, there is a long process leading to neoplastic changes. ${ }^{70}$ Experiments showed that ROS could arise indirectly due to the effects of internalized particles on the mitochondrial respiration system or in depletion of antioxidant species within the cell. Studies with nanoparticles (nano/ultrafine, cerium oxide, and hematite nanoparticles) showed that they have the potential to damage lung cells, leading to lung cancer, as well as to cause lipid peroxidation, depletion of glutathione levels after 72 hours' exposure to MRC-5 lung fibroblast cells. ${ }^{70-72}$

\section{Biokinetic mechanisms of ENPs in the body}

Understanding the biokinetics of ENPs in biological systems can provide important information on internal doses to 
secondary organs and is essential to designing and interpreting in vitro toxicity studies. Unlike free or loosely bound molecules, the transport, accumulation, transformation, and clearance of nanomaterials in the human body is intimately associated with physical form as well as chemical composition. ${ }^{73-76}$

Inhalation studies using iridium nanoparticles (15 and $80 \mathrm{~nm}$ ) have demonstrated the translocation of inhaled particles to extrapulmonary organs. ${ }^{77}$ Of particular concern from experimental studies has been the nature of interactions between nanoparticles and the central nervous system. ${ }^{78}$ Experiments showed that inhaled nanoparticles can translocate to the central nervous system via olfactory neurons following nasal deposition and induce significant inflammation-related effects. This transport route is unique to nanometer-scale particles and raises the possibility of previously unidentified organ-specific doses and responses. ${ }^{79,80}$

\section{Mechanisms of oxidative stress by ENPs at the cellular level}

The generation of ROS/RNS at the cellular level by ENPs subsequently causes oxidative damage to important biomolecules and depletion of antioxidant enzymes and small molecular-weight antioxidants (eg, ascorbic acid, vitamin E). The extent to which ROS accumulate is determined by the antioxidative system, which enables organisms to maintain proteins and other cellular components in an active state for metabolism. Redox homeostasis is governed by the presence of large pools of these antioxidants that buffer reductants and oxidants. Redox signal transduction is another universal feature of aerobic life honed through evolution to balance information from metabolism and the environment. Oxidative stress in aerobic life is the result of an imbalance between the production of ROS and a biological system's ability to detoxify the reactive intermediates or to repair the resulting damage. ${ }^{81-83}$

The scientific literature already contains experimental data showing that ENPs can generate ROS, which overwhelm antioxidant defenses in the cellular environment and, as a consequence, develop oxidative stress. This is considered a valid mechanism for toxicity studies of ENPs. ${ }^{84-86}$

It has been shown experimentally that water-soluble fullerenes, $\mathrm{TiO}_{2}$ nanoparticles, CNTs, and many other ENPs induce the production of ROS, lipid peroxidation, and oxidative stress, as well as generation of proinflammatory response in tissue cultures and in animal studies. Inevitably, respiratory oxidative stress is very prominent in inhalation studies of ENPs. The relative importance of oxidative stress lies in the ability to mediate to a number of active processes in the cells, such as apoptosis, DNA adduct formation and pro-inflammatory gene expression. Nanosized particles have high efficiency for deposition in the upper and lower regions of the respiratory tract and can be retained in the lungs for a long period of time. Potentially, ENPs can induce oxidative stress and cause greater inflammatory effects than their fine-sized equivalents. ${ }^{87-90}$

\section{Lung inflammation as a result of oxidative stress by ENPs}

Scientific evidence has shown that there is a close connection between oxidative stress in the cell and the elicitation of an inflammatory response via pro-inflammatory gene transcription. Many studies have reported pro-inflammatory effects of ENPs at various doses on pro-inflammatory gene expression in the cell. The redox-responsive nuclear factor (NF)- $\mathrm{KB}$ and activator protein (AP)-1 transcription factors have also been reported to be activated in mononuclear phagocytes (MNP)-exposed cells. ${ }^{91-93}$ In addition, numerous studies report the induction of inflammation itself in the lungs following deposition of ENPs by intratracheal installation or inhalation exposures. ${ }^{94}$

\section{Are ENPs potential carcinogenic orland genotoxic agents?}

The generation of ROS, oxidative stress, and inflammation by ENPs inevitably raises the question of carcinogenicity and/or genotoxicity. If nanoparticles can directly interact with the cellular DNA and cause mutagenic-type damage (oxidative, strand breaks, lesions, adducts, etc), they can promote mechanisms of carcinogenesis.

Some of the studies of genotoxicity of ENPs were focused on transition metals, which are the largest source of nanomaterials. The nanosize of these metallic particles means they are easily transported into biological systems, thus raising the question of their toxic and carcinogenic effects on the susceptible systems. Scientists suggest that, although advances have been made and insights have been gained on the effect of ENPs with transitional metals (Co, $\mathrm{Ni}, \mathrm{Cu}$ ), there remains much ground to be covered, particularly with respect to our knowledge on their genotoxic and carcinogenic effects. ${ }^{95}$

A recent review (2011) compared in vitro genotoxicity studies for inorganic nanomaterials with occupational exposure studies of carcinogenicity and epidemiological data. Nearly all types of nanomaterials and control dusts 
used in the in vitro assays showed genotoxic effects in cell cultures, such as cobalt-chromium ( $\mathrm{Co}-\mathrm{Cr}$ ) particles, diesel soot, $\mathrm{SiO}_{2}$ (crystalline and amorphous), $\mathrm{TiO}_{2}$, carbon black; however, this was not consistent in all studies. The overall results of these studies showed that only about $50 \%$ were positive. ${ }^{96}$

Nanoparticles with reactive surfaces may undoubtedly generate inflammation more readily, and inflammation could be sufficiently intense to lead to secondary carcinogenesis via the oxidants that can damage important biomolecules and mitogens produced during inflammation. There is some evidence in vitro that ENPs can penetrate cellular membranes and gain access to the genetic material of the nucleus. Recent studies also suggest some similarities between the pathogenic properties of multi-walled CNTs and those of asbestos fibers. CNTs can cause genetic aberrations by a primary mechanism additional to the inflammation-mediated mechanism. ${ }^{97-99}$

A review (2009) examined a number of studies investigating the carcinogenic potential of ENP materials, such as $\mathrm{TiO}_{2}$, carbon black, CNT, and fullerenes, to the lung of female rats. CNT-induced mesotheliomas were applied intraperitoneally in rats and mice. Data for fullerenes $\left(\mathrm{C}_{60}\right)$ were insufficient to evaluate carcinogenic risk. Sub-chronic toxicity data indicated that, in general, nanoparticles form aggregates and agglomerates and cause foreign body reactions at their applied sites with inflammatory cells, including macrophage infiltration. ${ }^{100}$ These findings are similar to those regarding the biological effects of asbestos, a potent carcinogen, and indicate that careful risk assessment of ENPs is still in the phase of in vivo experimentation. Therefore, it will take a number of years to prove carcinogenic risk to humans and to allow for extensive epidemiological studies. ${ }^{101-103}$

Metal and metal oxide nanoparticles have a prominent position in the engineered nanoproducts, and there is a wide range of applications for a variety of ENMs. Inevitably, research on their cytotoxicity and carcinogenic potential is considered very important, as is their potential for adverse health effects and safety problems. A recent review (2012) summarized genotoxic effects of metal nanoparticles from recent scientific literature. The studies indicated that some types of metal nanoparticles can cause both DNA strand breaks and chromosomal damages in experimental animals. However, their genotoxic effects depend not only on particle size, surface modification (particle coating), and exposure route, but also on exposure duration. The reviewers noted that, due to considerable inconsistencies in the results and the lack of standardized test methods, a reliable hazard assessment of metal nanoparticles is still limited. ${ }^{104}$
Metal oxide nanoparticles that are used in various ENMs are also under investigation for potential exposure and hazards. A 2010 review focused on $\mathrm{ZnO}$ nanoparticles destined for use in modern sunscreens, and discuss the potential for human exposure and the health hazard at each stage of their manufacture (for exposed workers and consumers who were going to use the sunscreen products). The reviewers examined many research papers but could not reach a firm conclusion as to the hazards; they highlighted a need for further research. ${ }^{105}$

Gold and silver nanoparticles also have many applications in various ENMs. A 2010 review focused on the safety and evaluation of toxicity associated with human exposure to silver and gold nanoparticles, due to the relative abundance of toxicity data available for these particles. From past studies, it is known that inflammatory, oxidative, genotoxic, and cytotoxic consequences are associated with silver particulate exposure. The primary site of gold and silver particulate accumulation has also been demonstrated to be the liver (in vitro studies). However, in general, there is a lack of in vivo and in vitro toxicity information that allows correlations between the findings to be made. Instead, a focus on the tissue distribution of particles following exposure is evident within the available literature. ${ }^{106}$

Despite the uncertainties or mixed results of the in vivo studies, the findings to date on the carcinogenic potential of nanomaterials must be taken seriously, and precautionary measures to minimize exposure should go hand in hand with the development of a comprehensive and conclusive toxicological methodology and testing procedure for nanostructured materials that includes all possible exposure routes. Furthermore, criteria for evaluating nano-specific carcinogenic properties should be constantly updated and adapted to the state of knowledge. There is a need here for amendments to be made to EU legislation, as currently various ENMs and certain types of nanoparticles do not represent a separate category of substance in their own right. ${ }^{107}$

\section{Conclusion}

The nanotechnology field is a fast-growing technological field with significant breakthroughs, and several products are commercially available. Studies in vitro and in vivo, and past research on superfine particles in the last decade, have shown that the toxicological data for ENPs, although are very incomplete until now, are adequate to alert scientists as to future health and safety problems for workers and consumers. In particular, inhaled nanoparticles can 
cause extensive oxidative damage and inflammation of the respiratory system and end up in the bloodstream or the nervous system. ENPs are so tiny that small quantities could have major toxic effects in the respiratory system. Despite the uncertainties, many scientists suggest that the findings to date on the carcinogenic potential of nanomaterials must be taken seriously. H\&S authorities must develop comprehensive toxicological methodology and testing procedures for ENPs. Criteria for evaluating the carcinogenic properties of ENPs should constantly be updated and adapted to the state of knowledge. There is a need for amendments to be made to legislation in the EU and in developed countries to cover specific H\&S problems of ENPs and the commercial applications of nanoproducts.

\section{Disclosure}

The authors report no conflicts of interest in this work.

\section{References}

1. bcc Research. Nanotechnology [webpage on the Internet]. Wellesley: BCC Research LLC; 2013. Available from: http://www.bccresearch. com/market-research/nanotechnology/. Accessed October 17, 2013.

2. Roco MC. The long view of nanotechnology development: the National Nanotechnology Initiative at 10 years. J Nanopart Res. 2011; 13(2):427-445.

3. Drexler KE. Engines of Creation: The Coming Era of Nanotechnology. New York: Anchor Books/Doubleday; 1986.

4. Johal MS. Understanding Nanomaterials. Boca Raton (FL): CRC Press (Taylor and Francis Group); 2011.

5. Ozin GA, Arsenault A, Cademartiri L. Nanochemistry: A Chemical Approach to Nanomaterials. 2nd revised ed. Cambridge: RSC Publishing; 2008.

6. Mulhall D. Our Molecular Future: How Nanotechnology, Robotics, Generics, and Artificial Intelligence Will Transform Our World. Amherst (NY): Prometheus Books; 2002.

7. Ochsner A, Shokuhfar A, editors. New Frontiers of Nanoparticles and Nanocomposite Materials: Novel Principles and Techniques. New York: Springer; 2013.

8. Foster LE. Nanotechnology: Science, Innovation, and Opportunity. New York: Prentice Hall; 2005.

9. Department of Health and Human Services, Centers for Disease Control and Prevention, National Institute for Occupational Safety and Health. Current Intelligence Bulletin 65. Occupational Exposure to Carbon Nanotubes and Nanofibers. Washington, DC: NIOSH: 2013. Available from: http://www.cdc.gov/niosh/docs/2013-145/pdfs/2013-145.pdf. Accessed September 30, 2013.

10. Department of Health and Human Services, Centers for Disease Control and Prevention, National Institute for Occupational Safety and Health. Progress Toward Safe Nanotechnology in the Workplace: A Report from the NIOSH Nanotechnology Research Center. Cincinnati (OH): NIOSH; 2007. Available from: http://www.cdc.gov/niosh/docs/2007-123/ pdfs/2007-123.pdf. Accessed September 30, 2013.

11. Kosk-Bienko J, editor. European Agency for Safety and Health at Work. Workplace Exposure to Nanoparticles. Bilbao: EU-OSHA; 2009. Available from: https://osha.europa.eu/en/publications/literature_reviews/ workplace_exposure_to_nanoparticles. Accessed September 30, 2013.

12. Del Castillo AMP. Nanomaterials and Workplace Health and Safety: What Are the Issues for Workers? Brussels: ETUI Publications (The European Trade Union Institute); 2013.
13. Valavanidis A, Fiotakis K, Vlachogianni T. Airborne particulate matter and human health: toxicological assessment and importance of size and composition of particles for oxidative damage and carcinogenic mechanisms. J Environ Sci Health CEnviron Carcinog Ecotoxicol Rev. 2008;26(4):339-362.

14. Møller P, Folkmann JK, Forchhammer L, et al. Air pollution, oxidative damage to DNA, and carcinogenesis. Cancer Lett. 2008;266(1): 84-97.

15. Møller P, Jacobsen NR, Folkmann JK, et al. Role of oxidative damage in toxicity of particulates. Free Radic Res. 2010;44(1):1-46.

16. Li N, Xia T, Nel AE. The role of oxidative stress in ambient particulate matter-induced lung diseases and its implications in the toxicity of engineered nanoparticles. Free Radic Biol Med. 2008;44:1689-1699.

17. Valavanidis A, Vlachogianni T, Fiotakis K. Tobacco smoke: involvement of reactive oxygen species and stable free radicals in mechanisms of oxidative damage, carcinogenesis and synergistic effects with other respirable particles. Int J Environ Res Public Health. 2009;6(2):445-462.

18. Valavanidis A, Vlachogianni T, Fiotakis K, Loridas S. Pulmonary oxidative stress, inflammation and cancer: respirable particulate matter, fibrous dusts and ozone as major causes of lung carcinogenesis through reactive oxygen species mechanisms. Int J Environ Res Public Health. 2013;10(9):3886-3907.

19. Nanotechnology and nanomaterials research [webpage on the Internet]. United States Environmental Protection Agency (EPA); 2013. Available from: http://www.epa.gov/nanoscience/. Accessed July 31, 2013.

20. US Food and Drug Administration. FDA issues two draft guidances related to nanotechnology applications in cosmetics and food substances [webpage on the Internet]. Available from: http://www.fda. gov/ScienceResearch/SpecialTopics/Nanotechnology/ucm301093.htm. Accessed October 17, 2013.

21. OECD Database on Research into the Safety of Manufactured Nanomaterials [database on the Internet]. Paris: Organisation for Economic Co-operation and Development (OECD); 2013. Available from: http:// www.oecd.org/science/nanosafety/ (Users can access the database through an internet interface at: http://webnet.oecd.org/NanoMaterials). Accessed August 31, 2013.

22. Organisation for Economic Co-operation and Development (OECD). Current Developments in Delegations on the Safety of Manufactured Nanomaterials - Tour de Table. Series on the Safety of Manufactured Nanomaterials. No 37. Paris: OECD Publications; February 13, 2013. Available from: http://search.oecd.org/officialdocuments/ displaydocumentpdf/?cote $=$ env $/ \mathrm{jm} / \mathrm{mono}(2013) 2 \&$ doclanguage $=$ en . Accessed October 17, 2013.

23. Fahmy B, Ding L, You D, Lomnicki S, Dellinger B, Cormier SA. In vitro and in vivo assessment of pulmonary risk associated with exposure to combustion generated fine particles. Environ Toxicol Pharmacol. 2010;29(2):173-182.

24. Kelly FJ, Fussell JC. Size, source and chemical composition as determinants of toxicity attributable to ambient particulate matter. Atmos Environ. 2012;60:504-526.

25. Aust AE, Cook PM, Dodson RF. Morphological and chemical mechanisms of elongated mineral particle toxicities. J Toxicol Environ Health B Crit Rev. 2011;14(1-4):40-75.

26. Terzano C, Di Stefano F, Conti V, Graziani E, Petroianni A. Air pollution ultrafine particles: toxicity beyond the lung. Eur Rev Med Pharmacol Sci. 2010;14(10):809-821.

27. Kreyling WG, Semmler-Behnke M, Möller W. Ultrafine particle-lung interactions: does size matter? J Aerosol Med. 2006;19(1):74-83.

28. Hopke PK, Rossner A. Exposure to airborne particulate matter in the ambient, indoor, and occupational environments. Clin Occup Environ Med. 2006;5(4):747-771.

29. Samet JM, Dominici F, Curriero FC, Coursac I, Zeger SL. Fine particulate air pollution and mortality in 20 US cities, 1987-1994. N Engl J Med. 2000;343(24):1742-1749.

30. Mehta S, Shin H, Burnett R, North T, Cohen AJ. Ambient particulate air pollution and acute lower respiratory infections: a systematic review and implications for estimating the global burden of disease. Air Qual Atmos Health. 2013;6(1):69-83. 
31. Knaapen AM, Borm PJ, Albrecht C, Schins RP. Inhaled particles and lung cancer. Part A: mechanisms. Int J Cancer. 2004;109(6):799-809.

32. Borm PJ, Schins RP, Albrecht C. Inhaled particles and lung cancer, part B: paradigms and risk assessment. Int J Cancer. 2004;110(1):3-14.

33. Ying Z, Kampfrath T, Thurston G, et al. Ambient particulates alter vascular function through induction of reactive oxygen and nitrogen species. Toxicol Sci. 2009;111(1):80-88.

34. Fubini B, Hubbard A. Reactive oxygen species (ROS) and reactive nitrogen species (RNS) generation by silica in inflammation and fibrosis Free Radic Biol Med. 2003;34(12):1507-1516.

35. Chuang HC, Cheng YL, Lei YC, Chang HH, Cheng TJ. Protective effects of pulmonary epithelial lining fluid on oxidative stress and DNA single-strand breaks caused by ultrafine carbon black, ferrous sulphate and organic extract of diesel exhaust particles.Toxicol Appl Pharmacol. 2013;266(3):329-334.

36. Van Berlo D, Hullmann M, Schins RPF. Toxicology of ambient particulate matter. EXS. 2012;101:165-217.

37. Gamble J. Lung cancer and diesel exhaust: a critical review of the occupational epidemiology literature. Crit Rev Toxicol. 2010;40(3):189-244.

38. Chen H, Goldberg MS, Villeneuve PJ. A systematic review of the relation between long-term exposure to ambient air pollution and chronic diseases. Rev Environ Health. 2008;23(4):243-297.

39. Green FH, Vallyathan V, Hahn FF. Comparative pathology of environmental lung disease: an overview. Toxicol Pathol. 2007;35(1): 136-147.

40. Roduner E. Size matters: why nanomaterials are different. Chem Soc Rev. 2006;35(7):583-592.

41. Albanese A, Tang PS, Chan WC. The effect of nanoparticle size, shape, and surface chemistry on biological systems. Annu Rev Biomed Eng. 2012;14:1-16.

42. Buzea C, Pacheco II, Robbie K. Nanomaterials and nanoparticles: sources and toxicity. Biointerphases. 2007;2(4):MR17-MR71.

43. Nel AE, Mädler L, Velegol D, et al. Understanding biophysicochemical interactions at the nano-bio interface. Nature Mater. 2009;8(7): 543-557.

44. Verma A, Stellacci F. Effect of surface properties on nanoparticle-cell interactions. Small. 2010;6(1):12-21.

45. Tsuji JS, Maynard AD, Howard PC, et al. Research strategies for safety evaluation of nanomaterials, part IV: risk assessment of nanoparticles. Toxicol Sci. 2006;89(1):42-50.

46. Jiang W, Kim BY, Rutka JT, Chan WC. Nanoparticle-mediated cellular response is size-dependent. Nat Nanotechnol. 2008;3(3):145-150.

47. Borm P, Klaessig FC, Landry TD, et al. Research strategies for safety evaluation of nanomaterials, part V: role of dissolution in biological fate and effects of nanoscale particles. Toxicol Sci. 2006;90(1):23-32.

48. Brunner TJ, Wick P, Manser P, et al. In vitro cytotoxicity of oxide nanoparticles: comparison to asbestos, silica, and the effect of particle solubility. Environ Sci Technol. 2006;40(14):4374-4381.

49. Karlsson HL, Cronholm P, Gustafsson J, Möller L. Copper oxide nanoparticles are highly toxic: a comparison between metal oxide nanoparticles and carbon nanotubes. Chem Res Toxicol. 2008;21(9): 1726-1732.

50. Song W, Zhang J, Guo J, Zhang J, et al. Role of the dissolved zinc ion and reactive oxygen species in cytotoxicity of $\mathrm{ZnO}$ nanoparticles Toxicol Lett. 2010;199(3):389-397.

51. Miller RJ, Bennett S, Keller AA, Pease S, Lenihan $\mathrm{HS} \mathrm{TiO}_{2}$ nanoparticles are phototoxic to marine phytoplankton. PLoS One. 2012; 7(1):e30321

52. Winnik FM, Maysinger D. Quantum dot cytotoxicity and ways to reduce it. Acc Chem Res. 2013;46(3):672-680.

53. Adams LK, Lyon DY, Alvarez PJ. Comparative eco-toxicity of nanoscale $\mathrm{TiO}_{2}, \mathrm{SiO}_{2}$, and $\mathrm{ZnO}$ water suspensions. Water Res. 2006; 40(19):3527-3532.

54. Zhu X, Zhu L, Duan Z, Qi R, Li R, Lang Y. Comparative toxicity of several metal oxide nanoparticle aqueous suspensions to Zebrafish (Danio rerio) early developmental stage. J Environ Sci Health A Tox Hazard Subst Environ Engin. 2008;43(3):278-284.
55. Kumar V, Kumari A, Guleria P, Yadav SK. Evaluating the toxicity of selected types of nanochemicals. Rev Environ Contam Toxicol. 2012;215:39-121.

56. Donaldson K, Poland CA. Inhaled nanoparticles and lung cancer: what we can learn from conventional particle toxicology. Swiss Med Wkly. 2012;142:w13547.

57. Oberdörster G, Oberdörste E, Oberdörster J. Nanotoxicology: an emerging discipline evolving from studies of ultrafine particles. Environ Health Perspect. 2005;113(7):823-839.

58. Oberdörster G. Safety assessment for nanotechnology and nano-medicine: concepts of nanotoxicology. J Intern Med. 2010;267(1):89-105.

59. Dahmann D, Taeger D, Kappler M, et al. Assessment of exposure in epidemiological studies: the example of silica dust. J Expo Sci Environ Epidemiol. 2008;18(5):452-461.

60. Valberg PA, Long CM, Sax SN. Integrating studies on carcinogenic risk of carbon black: epidemiology, animal exposures, and mechanism of action. J Occup Environ Med. 2006;48(12):1291-1307.

61. Berry G, Gibbs GW. An overview of the risk of lung cancer in relation to exposure to asbestos and of taconite miners. Regul Toxicol Pharmacol. 2008;52(Suppl 1):S218-S222.

62. Valavanidis A, Balomenou H, Macropoulou H, Zarodimos I. A study of the synergistic interaction of asbestos fibers with cigarette tar extracts for the generation of hydroxyl radicals in aqueous buffer solution. Free Radic Biol Med. 1996;20(6):853-858.

63. Mossman BT, Kamp DW, Weitzman SA. Mechanisms of carcinogenesis and clinical features of asbestos-associated cancers. Cancer Invest. 1996;14(5):466-480.

64. Nagai H, Toyokuni S. Biopersistent fiber-induced inflammation and carcinogenesis: lessons learned from asbestos toward safety of fibrous nanomaterials. Arch Biochem Biophys. 2010;502(1):1-7.

65. Seaton A, Tran L, Aitken R, Donaldson K. Nanoparticles, human health hazard and regulation. J R Soc Interface. 2009;7 Suppl 1:S119-S129.

66. Aitken RJ, Borm P, Donaldson, et al. Nanoparticles - one word: a multiplicity of different hazards. Nanotoxicology. 2009;3(4):263-264.

67. Balbus JM, Maynard AD, Colvin VL, et al. Meeting report: hazard assessment for nanoparticles - report from an interdisciplinary workshop. Environ Health Perspect. 2007;115(11):1654-1659.

68. Martin LD, Krunkosky TM, Dye JA, et al. The role of reactive oxygen and nitrogen species in the response of airway epithelium to particulates. Environ Health Perspect. 1997;105 Suppl 5:1301-1307.

69. Fubini B, Hubbard A. Reactive oxygen species (ROS) and reactive nitrogen species (RNS) generation by silica in inflammation and fibrosis. Free Radic Biol Med. 2003;34(12):1507-1516.

70. Liao CM, Chio CP, Chen WY, et al. Lung cancer risk in relation to traffic-related nano/ultrafine particle-bound PAHs exposure: a preliminary probabilistic assessment. J Hazard Mater. 2011;190(1-3): 150-158.

71. Culcasi M, Benameur L, Mercier A, et al. EPR spin trapping evaluation of ROS production in human fibroblasts exposed to cerium oxide nanoparticles: evidence for NADPH oxidase and mitochondrial stimulation. 2012;199(3):161-176.

72. Radu M, Munteanu MC, Petrache S, et al. Depletion of intracellular glutathione and increased lipid peroxidation mediate cytotoxicity of hematite nanoparticles in MRC-5 cells. Acta Biochim Pol. 2010;57(3): 355-360.

73. Möller W, Felten K, Sommerer K, et al. Deposition, retention, and translocation of ultrafine particles from the central airways and lung periphery. Am J Respir Crit Care Med. 2008;177(4):426-432.

74. Creutzenberg O. Biological interactions and toxicity of nanomaterials in the respiratory tract and various approaches of aerosol generation for toxicity testing. Arch Toxicol. 2012;86(7):1117-1122.

75. Liu Y, Gao Y, Zhang L, et al. Potential health impact on mice after nasal instillation of nanosized copper particles and their translocation in mice. J Nanosci Nanotechnol. 2009;9(11):6335-6343.

76. Zhu MT, Feng WY, Wang Y, et al. Particokinetics and extrapulmonary translocation of intratracheally instilled ferric oxide nanoparticles in rats and the potential health risk assessment. Toxicol Sci. 2009;107(2):342-351. 
77. Kreyling WG, Semmler-Behnke M, Seitz J, et al. Size dependence of the translocation of inhaled iridium and carbon nanoparticle aggregates from the lung of rats to the blood and secondary target organs. Inhal Toxicol. 2009;21 Suppl 1:55-60.

78. Yang Z, Liu ZW, Allaker RP, et al. A review of nanoparticle functionality and toxicity on the central nervous system. $J R$ Soc Interface. 2010; 7 Suppl 4:S411-S422.

79. Oberdöster E. Manufactured nanomaterials (fullerenes, C60) induce oxidative stress in the brain of juvenile largemouth bass. Environ Health Perspect. 2004;112(10):1058-1062.

80. Elder A, Gelein R, Silva V, et al. Translocation of inhaled ultrafine manganese oxide particles to the central nervous system. Environ Health Perspect. 2006;114(8):1172-1178.

81. Davies KJ. Oxidative stress: the paradox of aerobic life. Biochem Soc Symp. 1995;61:1-31.

82. Jones DP. Redefining oxidative stress. Antioxid Redox Signal. 2006; 8(9-10):1865-1879.

83. Jones DP. Radical-free biology of oxidative stress. Am J Physiol Cell Physiol. 2008;295(4):C849-C868.

84. Xia T, Kovochich M, Brant J, et al. Comparison of the abilities of ambient and manufactured nanoparticles to induce cellular toxicity according to an oxidative stress paradigm. Nano Lett. 2006;6(8): $1794-1807$

85. von Moos N, Slaveykova VI. Oxidative stress induced by inorganic nanoparticles in bacteria and aquatic microalgae: state of the art and knowledge gaps. Nanotoxicology. Epub June 19, 2013.

86. Kim S, Ryu DY. Silver nanoparticle-induced oxidative stress, genotoxicity and apoptosis in cultured cells and animal tissues. J Appl Toxicol. 2013;33(2):78-89.

87. Mocan T, Clichici S, Agoşton-Coldea L, et al. Implications of oxidative stress mechanisms in toxicity of nanoparticles (review). Acta Physiol Hung. 2010;97(3):247-255.

88. Li N, Xia T, Nel AE. The role of oxidative stress in ambient particulate matter-induced lung diseases and its implications in the toxicity of engineered nanoparticles. Free Radic Biol Med. 2008;44(9):1689-1699.

89. Madl AK, Pinkerton KE. Health effects of inhaled engineered and incidental nanoparticles. Crit Rev Toxicol. 2009;39(8):629-658.

90. Donaldson K, Aitken R, Tran L, et al. Carbon nanotubes: a review of their properties in relation to pulmonary toxicology and workplace safety. Toxicol Sci. 2006;92(1):5-22.

91. Cho WS, Duffin R, Poland CA, et al. Differential pro-inflammatory effects of metal oxide nanoparticles and their soluble ions in vitro and in vivo; zinc and copper nanoparticles, but not their ions, recruit eosinophils to the lungs. Nanotoxicology. 2012;6(1):22-35.

92. Mroz RM, Schins RP, Li H, Drost EM, Macnee W, Donaldson K, et al. Nanoparticle carbon black driven DNA damage induces growth arrest and AP-1 and NFkappaB DNA binding in lung epithelial A549 cell line. J Physiol Pharmacol. 2007;58 Suppl 5(Pt 2):461-470.
93. Li R, Ning Z, Majumdar R, et al. Ultrafine particles from diesel vehicle emissions at different driving cycles induce differential vascular proinflammatory responses: implication of chemical components and NF-kappaB signaling. Part Fibre Toxicol. 2010;7:6.

94. Shvedova AA, Kisin E, Murray AR, et al. Inhalation vs aspiration of single-walled carbon nanotubes in C57BL/6 mice: inflammation, fibrosis, oxidative stress, and mutagenesis. Am J Physiol Lung Cell Mol Physiol. 2008;295(4):L552-L565.

95. Magaye R, Zhao J, Bowman L, Ding M. Genotoxicity and carcinogenicity of cobalt-, nickel- and copper-based nanoparticles. Exp Ther Med. 2012;4(4):551-561.

96. Roller M. In vitro genotoxicity data of nanomaterials compared to carcinogenic potency of inorganic substances after inhalational exposure. Mutat Res. 2011;727(3):72-85.

97. Bonner JC. Carbon nanotubes as delivery systems for respiratory disease: do the dangers outweigh the potential benefits? Expert Rev Respir Med. 2011;5(6):779-787.

98. Stella GM. Carbon nanotubes and pleural damage: perspectives of nanosafety in the light of asbestos experience. Biointerphases. 2011;6(2):P1-P17.

99. Shvedova AA, Kisin ER, Porter D, et al. Mechanisms of pulmonary toxicity and medical applications of carbon nanotubes: two faces of Janus? Pharmacol Ther. 2009;121(2):192-204.

100. Tsuda H, Xu J, Sakai Y, Futakuchi M, Fukamachi K. Toxicology of engineered nanomaterials: a review of carcinogenic potential. Asian Pac J Cancer Prev. 2009;10(6):975-980.

101. Sakamoto Y, Nakae D, Fukumori N, et al. Induction of mesothelioma by a single intrascrotal administration of multi-wall carbon nanotube in intact male Fischer 344 rats. J Toxicol Sci. 2009;34(1):65-76.

102. Sera N, Tokiwa H, Miyata N. Mutagenicity of the fullerene C60generated singlet oxygen dependent formation of lipid peroxides. Carcinogenesis. 1996;17(10):2163-2169.

103. Takagi A, Hirose A, Nishimura T, et al Induction of mesothelioma in $553+/-$ mouse by intraperitoneal application of multi-wall carbon nanotube. J Toxicol Sci. 2008;33(1):105-116.

104. Klien K, Godnić-Cvar J. Genotoxicity of metal nanoparticles: focus on in vivo studies. Arh Hig Rada Toksikol. 2012;63(2):133-145.

105. Osmond MJ, McCall MJ. Zinc oxide nanoparticles in modern sunscreens: an analysis of potential exposure and hazard. Nanotoxicology. 2010;4(1):15-41.

106. Johnston HJ, Hutchison G, Christensen FM, Peters S, Hankin S, Stone $\mathrm{V}$. A review of the in vivo and in vitro toxicity of silver and gold particulates: particle attributes and biological mechanisms responsible for the observed toxicity. Crit Rev Toxicol. 2010;40(4):328-346.

107. Becker H, Herzberg F, Schulte A, Kolossa-Gehring M. The carcinogenic potential of nanomaterials, their release from products and options for regulating them. Int J Hyg Environ Health. 2011;214(3): 231-238.

\section{Publish your work in this journal}

Lung Cancer: Targets and Therapy is an international, peer-reviewed, open access journal focusing on lung cancer research, identification of therapeutic targets and the optimal use of preventative and integrated treatment interventions to achieve improved outcomes, enhanced survival and quality of life for the cancer patient. Specific topics Cellular research and biomarkers; Identification of biotargets and agents with novel Submit your manuscript here: http://www.dovepress.com/lung-cancer-targets--therapy-journa

\section{Dovepress}

mechanisms of action; Optimal clinical use of existing anticancer agents, including combination therapies; Radiation and surgery; Palliative care; Patient adherence, quality of life, satisfaction; Health economic evaluations. The manuscript management system is completely online and includes a very quick and fair peer-review system. Visit http://www.dovepress.com/testimonials.php to read real quotes from
published authors. 